\title{
CLINICO-EPIDEMIOLOGICAL STUDY OF NEW LEPROSY CASES IN A RURAL TERTIARY CARE CENTRE IN CENTRAL INDIA
}

\author{
Parikshit Sharma1, Akhil Shah², Rohini Chauhan ${ }^{3}$
}

${ }^{1}$ Associate Professor, Department of Skin \& VD, Index Medical College, Indore.

${ }^{2}$ Assistant Professor, Department of Skin \& VD, Index Medical College, Indore.

${ }^{3}$ Postgraduate Resident, Department of Skin \& VD, Index Medical College, Indore.

\section{ABSTRACT}

\section{BACKGROUND}

Leprosy is a chronic infectious disease caused by Mycobacterium leprae, affecting the skin, the peripheral nerves, mucosa of the upper respiratory tract and also the eyes, apart from some other structures. The area served by our center falls in those few endemic regions with dist. Indore having prevalence rate of 1.12/10,000 population as on March, 2015 Hence, the present study was performed to analyse the profile and magnitude of leprosy patients subsequently assessing the current situation of leprosy at a tertiary level referral center in central India.

\section{MATERIALS AND METHODS}

All cases of leprosy registered at the Leprosy Clinic of Index Medical College during the duration of 4 years (Between May 2012 and May 2016) were retrospectively analysed. Based on history, clinical features, slit skin smear, skin biopsy (Whenever required), the disease spectrum (Ridley-Jopling classification) ${ }^{[4]}$ was determined. Further detailed analysis was done based on age, sex, spectrum, reactions, special forms of leprosy.

\section{RESULTS}

A total of 97 patients were diagnosed as having leprosy during the period of 4 years (May 2012 to May 2016). More than 50\% of patients were middle aged ( 21 to $40 \mathrm{yrs}$.). $8.25 \%$ patients were aged less than $20 \mathrm{yrs}$. $82.5 \%$ cases were males and $17.5 \%$ females. In our study, maximum number of cases were of Lepromatous leprosy followed by patients of the Borderline Tuberculoid spectrum, Tuberculoid, Borderline lepromatous, and mid-borderline spectrum. Majority of the patients who had reactions were in Type 1 reaction.

\section{CONCLUSION}

Leprosy is a chronic infection which in India is relatively more prevalent than other parts of world. Very few clinicoepidemiological surveys have been carried out at a tertiary level care center, and even less are in central India, especially Madhya Pradesh. Our hospital caters/serves the rural population in Indore district which is a high prevalence zone. Despite efforts by govt. agencies and NGOs we found so many new leprosy cases. This calls for the need to create better awareness and knowledge about the disease in deeper roots of rural India.

\section{KEYWORDS}

Leprosy, Epidemiology, Spectrum, Central India.

HOW TO CITE THIS ARTICLE: Sharma P, Shah A, Chauhan R. Clinico-epidemiological study of new leprosy cases in a rural tertiary care centre in Central India. J. Evolution Med. Dent. Sci. 2017;6(14):1077-1079, DOI: 10.14260/jemds/2017/233

\section{BACKGROUND}

Leprosy is a chronic infectious disease caused by Mycobacterium leprae, an acid-fast, rod-shaped bacillus. The disease mainly affects the skin, the peripheral nerves, mucosa of the upper respiratory tract and also the eyes, apart from some other structures. In 1955 National Leprosy Control Programme (NECP) was launched in India based on Dapsone monotherapy.[1] In 1983 National Leprosy Eradication Programme (NCEP) was launched with Introduction of Multidrug therapy (MDT) in phases, as recommended by WHO.[1]

Financial or Other, Competing Interest: None.

Submission 22-11-2016, Peer Review 06-12-2016,

Acceptance 08-12-2016, Published 15-02-2017.

Corresponding Author:

Dr. Parikshit Sharma,

\#EK 387, Sch No. 54, Opposite

Hotel Fortune Landmark,

Vijaynagar, Indore-452010.

E-mail: drparikshitsharma@gmail.com

DOI: $10.14260 /$ jemds $/ 2017 / 233$

\section{(c) $(1) \ominus$}

By 2005, elimination of Leprosy at National Level was achieved (Prevalence rate being $0.69 / 10,000$ on $1^{\text {st }}$ April 2015).[1]

Till then 33 States/UTs had attained the level of leprosy elimination. 542 districts (82.5\%) out of total 657 districts also achieved elimination by March 2014. A few districts and blocks continue to have a prevalence $>1 / 10,000 .{ }^{[2]}$

The area served by our centre falls in those few endemic regions with dist. Indore having prevalence rate of 1.12/10,000 population as on March, 2015.[3]

Hence, the present study was performed to analyse the profile and magnitude of leprosy patients subsequently assessing the current situation of leprosy at a tertiary level referral center in central India.

\section{MATERIALS AND METHODS}

All cases of leprosy registered at the Leprosy Clinic of Index Medical College during the duration of 4 years (Between May 2012 and May 2016) were retrospectively analysed. No active case finding or survey was carried out and all the cases were those who had themselves reported to the OPD. 
Based on history, clinical features, slit skin smear, skin biopsy (Whenever required), the disease spectrum (RidleyJopling classification) ${ }^{[4]}$ was determined.

Further detailed analysis was done based on age, sex, spectrum, reactions, special forms of leprosy.

Treatment was started according to the multibacillary or paucibacillary status and the patients were periodically followed up for their compliance.

\section{RESULTS}

A total of 97 patients were diagnosed as having leprosy during the period of 4 years (May 2012 to May 2016).

Following observations were made:

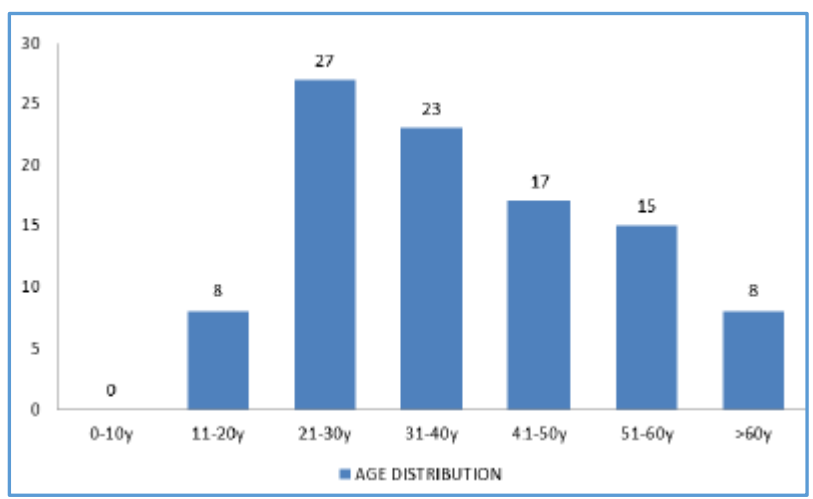

Figure 1. Age Distribution

More than $50 \%$ of patients were middle aged (21 to 40 yrs.). $8.25 \%$ patients were aged less than 20 yrs. A significant number of patients $(8.25 \%)$ were above $60 \mathrm{yrs}$. of age.

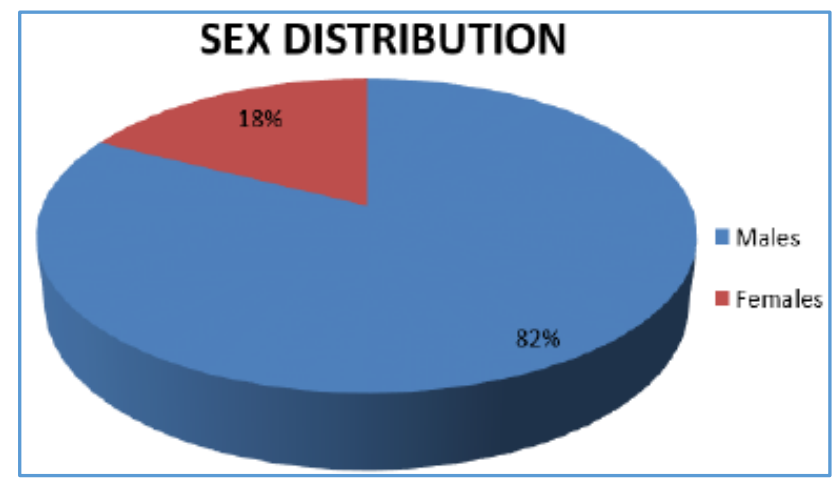

Figure 2. Sex Distribution

$82.5 \%$ cases were males and $17.5 \%$ females. The male to female ratio was 4.70 .

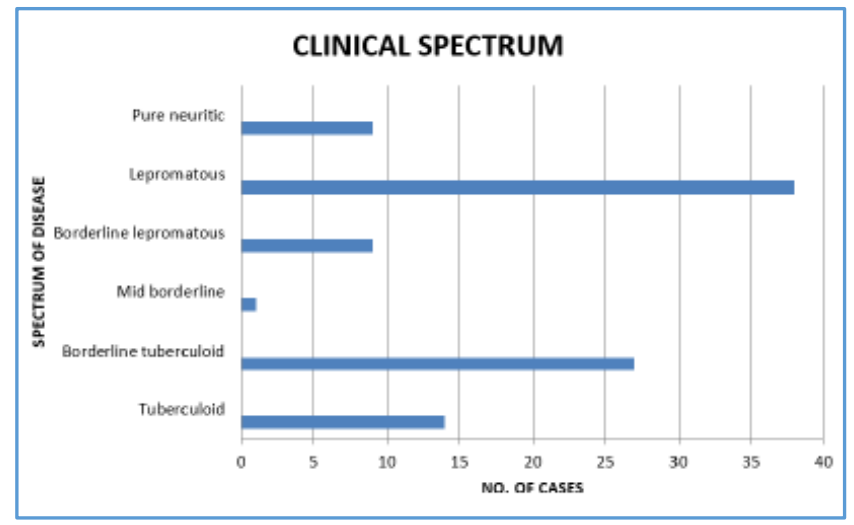

Figure 3. Spectrum of the Disease
In our study, maximum number of cases, $39.18 \%(n=38)$, were of Lepromatous leprosy. These were followed by patients of the Borderline Tuberculoid spectrum, 27.84\% (n= 27) $14.43 \%(n=14) ; 9.28 \%(n=9) ; 1.03 \%(n=1)$ were in Tuberculoid, Borderline Lepromatous, and mid-borderline spectrum respectively. 9 cases $(9.28 \%)$, were found to have only nerve involvement and were categorised as pure neuritic leprosy. Out of all the patients of LL, 2 patients were diagnosed having histoid leprosy.

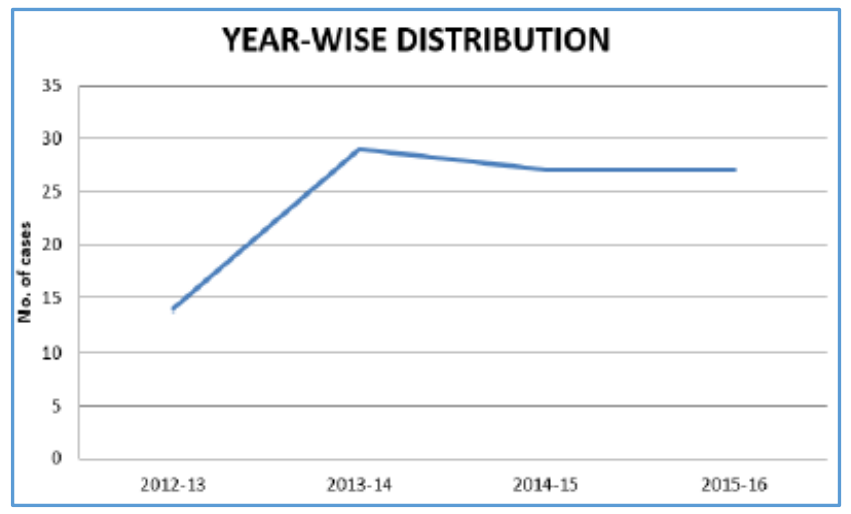

Figure 4. Year-wise Distribution

The analysis was done starting from $1^{\text {st }}$ May 2012, and thereafter the data was analysed every 12 months ( 1 st May to $31^{\text {st }}$ April). In our study for the tenure 2012-13, we observed 17 cases of leprosy.

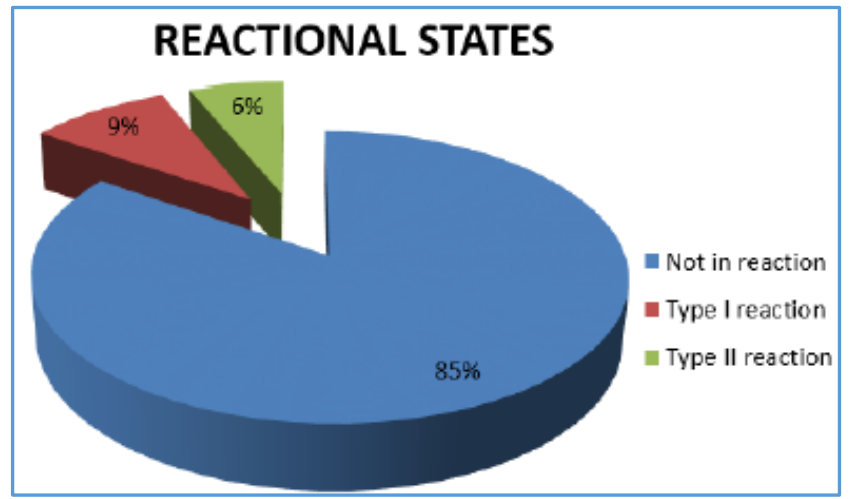

Figure 5. Reactions

Total of $15.46 \%(n=15)$ patients presented in reaction, of which $60 \%(n=9)$ were in type 1 and $40 \%$ were in type 2 reaction. 14 cases were recorded in the year 2012-13; 29 cases in 2013-14; 27 cases in 2014-15 and 27 cases in the year 201516.

\section{DISCUSSION}

Our study was based on data of patients who had selfreported at our tertiary care center that caters mostly to the rural population in Indore district in central India (Madhya Pradesh).

In our study, the majority of patients (50\%) were between 21 and 40 yrs. of age. We also noticed a significant number $(8.25 \%)$ of elderly patients ( $>60 \mathrm{yrs}$.) suffering from the disease. None of our patients were below $10 \mathrm{yrs}$. of age. In consensus with other studies and national scenario, males outnumbered females (M:F= 4.7:1), probably due to the fact 
that males do self-report and female health issues are often neglected, more so in rural populations.

Contrary to other studies, Indian J Dermatol. 2015 JanFeb; 60(1): 55-59., Indian J Lepr. 2009 Oct-Dec; 81(4):173-9, we had highest percentage of Lepromatous cases $(39.18 \%)$, followed by Borderline tuberculoid spectrum (27.84\%). A notable fact was that a good number of patients (9.28\%) had only nerve involvement (Pure neuritic type) without any skin lesions. A predominance of lepromatous leprosy might be due to the late presentation of the rural patients to a tertiary centre, owing to lack of awareness, wrong diagnosis and management, and improper penetration of health care facilities, resulting in downgrading of the disease in due course of time.

In the study, $15.45 \%$ patients had reaction at initial presentation, mostly Type 1 and this is in accordance with findings in earlier similar study.

\section{CONCLUSION}

Leprosy is a chronic infection which in India is relatively more prevalent than other parts of world. Along with the chronic and stubborn nature of this infection is also attached very strong social stigma which plays a major role in shaping psychological state of affected individual. Very few clinicoepidemiological surveys have been carried out at a tertiary level care center, and even less are in central India specially Madhya Pradesh. Our hospital caters/serves the rural population in Indore district which has 1.12 cases per lakh population and falls in high prevalence zone $(>1 / 1,00,000)$ as per March 2015 data of NLEP.[1]

Despite efforts by govt. agencies and NGOs, we found so many new leprosy cases. This calls for the need to create better awareness and knowledge about the disease in deeper roots of rural India. Those not aware or not reporting their ailment should be pursued not to ignore it in view of early and timely medical intervention and regular follow-up for treatment to minimise the associated complications. Further, it is proposed that proper basic training of PHC doctors or workers to diagnose or suspect the disease should be routinely done inorder to avoid misdiagnosis and prompt referral of doubtful cases to a tertiary health care facility so that immediate and proper treatment can be initiated thereby reducing the burden of the disease in the society.

\section{REFERENCES}

[1] http://nlep.nic.in/about.html.

[2] Chhabra N, Grover C, Singal A, et al. Leprosy Scenario at a Tertiary Level Hospital in Delhi: A 5-year Retrospective Study Indian J Dermatol 2015;60(1):55-9.

[3] http://nlep.nic.in/Disttwise NCDR-Mar.15.

[4] Ridley DS. Histological classification and the immunological spectrum of leprosy. Bull World Health Organ 1974;51(5):451-65. 